Original Research

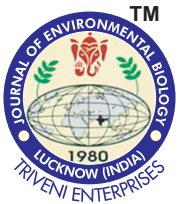

DOI : http://doi.org/10.22438/jeb/39/6/MRN-735
Journal Home page : www.jeb.co.in « E-mail : editor@jeb.co.in Journal of Environmental Biology

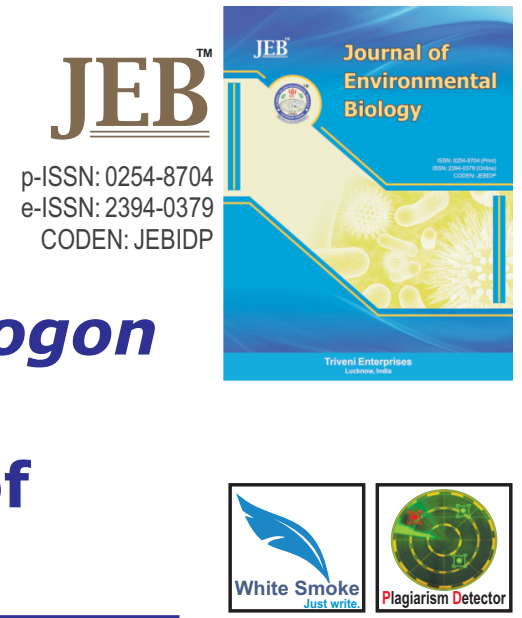

\title{
Antimicrobial activity of Cymbopogon citratus essential oil against the mycoflora of stored dried fruits of Zanthoxylum armatum
}

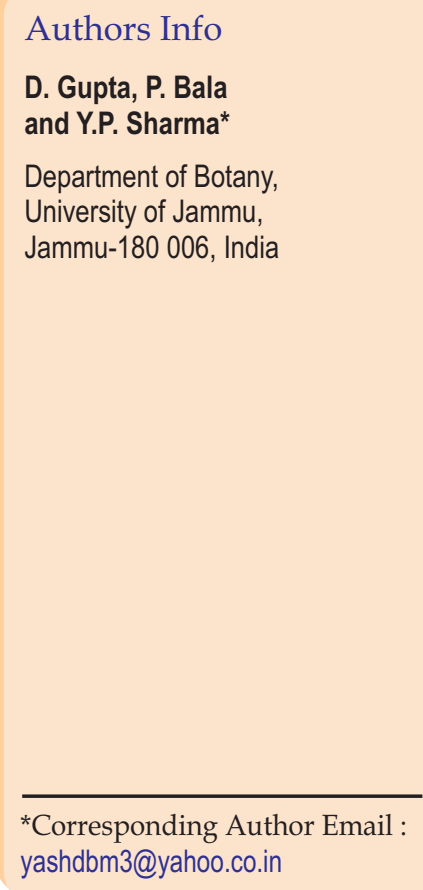

Key words

Aflatoxin $\mathrm{B}_{1}$

Antifungal

Aspergillus flavus

Cymbopogon citratus

Essential oil

Publication Info

Paper received : 29.08 .2017

Revised received : 11.01 .2018

Re-revised received: 10.03 .2018

Accepted : 14.03.2018

\section{Abstract}

Aim : The study aimed to investigate the fungal contamination in dried fruits of Zanthoxylum armatum and the effect of essential oil of Cymbopogon citratus against the deteriorating fungi and aflatoxin production by Aspergillus flavus.

Methodology : Mycoflora analysis of dried fruits of $Z$. armatum was done by dilution plate technique, while the antifungal assay of essential oil of $C$. citratus against seven isolated moulds was carried out by poisoned food technique. Aflatoxigenic potential of Aspergillus flavus and anti-aflatoxigenic activity of essential oil of $C$. citratus was done by spectrophotometric method.

Results : A total of 17 fungal species were isolated with Aspergillus as the predominant genus. The characterization of $C$. citratus essential oil revealed $\alpha$ - citral and $\beta$ - citral as major components. Essential oil significantly exhibited antifungal activity against the growth of tested fungal species. The minimal inhibitory concentration of essential oil was found to be $1.5 \mu \mathrm{ml}^{-1}$ for Fusarium graminearum, $2.5 \mu \mathrm{l} \mathrm{ml}{ }^{-1}$ for Alternaria

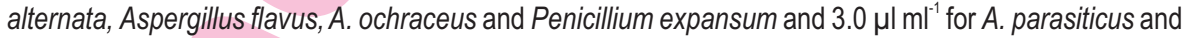
$P$. citrinum, respectively. The essential oil completely checked the production of aflatoxin $B_{1}$ by the toxigenic strains of $A$. flavus.

Interpretation : Both mycelial growth and aflatoxin $\mathrm{B}_{1}$ production followed a declining trend with an increase in essential oil concentration, demonstrating its practical efficacy as a plant based antimicrobial for enhancing the shelf-life of $Z$. armatum.

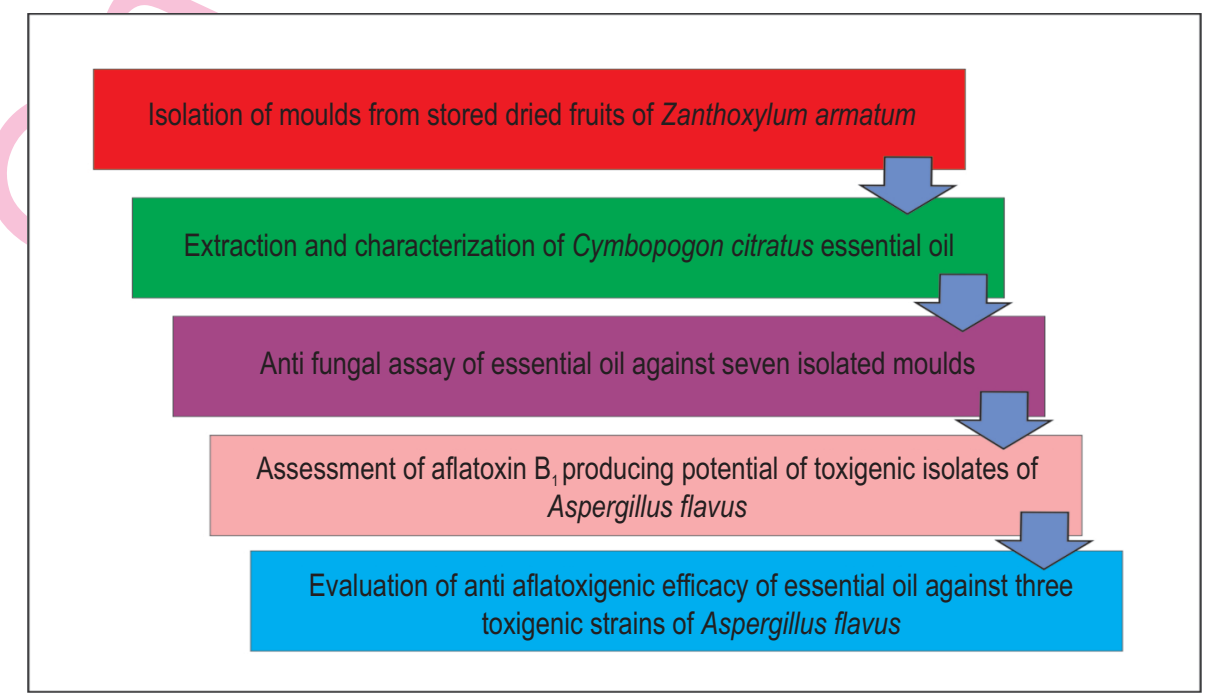




\section{Introduction}

Dried fruits are an important group of agricultural and confectionary commodities being used since the dawn of human civilization all over the world. Owing to their flavour, taste and indispensable nutrients, an array of health protective bioactive ingredients ideally increase the diet quality and help to decrease the risk of unrelieved diseases (Chang et al., 2016). Moisture content of dried fruits varies from 2 to $22 \%$ and further reduction in the water content of these commodities by drying inhibits microbial growth and slows down enzymatic reactions (Vinson et al., 2005). In general, most of the dried commodities have adequately low water activity to slow down bacterial growth However, filamentous moulds, especially the xerophilic moulds are the most important micro-organisms in dried fruits in terms of biodeterioration, if their drying and storage is inadequate. Some of the deteriorating moulds are also potential producers of various mycotoxins. Among these, aflatoxins produced by the Aspergillus flavus and other related species are the most important mycotoxins occurring in food and feed (Udomkun et al., 2017). Use of these contaminated commodities causes aflatoxicosis, a disease having symptoms of abnormal liver functioning, depressed immune response, carcinogenesis etc. (Shukla et al., 2009). To prolong the shelf-life of dried fruits and prevent the growth of filamentous fungi and production of aflatoxins, it is imperative to establish an ideal preservative.

Currently, to manage storage moulds in dried commodities, most of the synthetic chemicals used during postharvest treatment are man-made xenobiotics whose unabated applications have led to the development of fungal resistance as well as residual toxicity (Brent and Hollomon, 1998). They are also responsible for the stimulation of aflatoxin biosynthesis (Jayashree and Subramanyam, 2000). The present discussion on the negative effects of synthetic preservatives has also renewed interest of researchers towards natural food additives to improve the shelf-life of food commodities and to protect them from infesting microbes. One of such alternatives is the application of eco-friendly, cost-effective botanicals to minimize fungal deterioration of agricultural commodities and to improve their quality (Burt, 2004).

Since, the essential oils of higher plants and their components are highly volatile and biodegradable, they are easily accepted by consumers. Consequently, there is an increasing attention worldwide by various researchers to study the antimicrobial activities of various plant extracts to control moulds in stored food commodities that pose less risk to human health and environment (Weckesser et al., 2007; Gandomi et al., 2009; El-Nagerabi et al., 2013). Cymbopogon citratus (DC.) Stapf (Lemon grass) is known to possess various antimicrobial, antidiarrheal and antioxidant attributes owing to the presence of terpenoids, phenolic compounds and essential oils (Tzortzakis and Economakis, 2007; Manvitha and Bidya, 2014; Mosquera et al., 2016; Kausar et al., 2017; Oliveira et al., 2018). Therefore, the present study was undertaken to screen the fungi responsible for deteriorating stored dried fruits of Zanthoxylum armatum (locally known as timbru) and detection of toxigenic strains of Aspergillus flavus among these spoilage moulds. Also, the essential oil of $C$. citratus was evaluated for its antifungal and anti-aflatoxigenic activity in order to assess its efficacy as a prospective food additive.

\section{Materials and Methods}

Procurement of dried fruits : A total of 64 samples ( $200 \mathrm{~g}$ each) of dried fruits of Zanthoxylum armatum were purchased from households, wholesalers, markets and retail shops in different localities of Jammu province (Jammu, Reasi, Kathua, Rajouri, Poonch, Samba and Udhampur). The samples were collected in sterilized polythene bags, sealed over flame to prevent further contamination and stored at low temperature $\left(5^{\circ} \mathrm{C}\right)$ for further mycoflora and mycotoxin analysis.

Mycoflora analysis : The filamentous fungi of dried fruits of $Z$. armatum were isolated by dilution plate technique following the method of Singh et al. (1991). $10 \mathrm{gm}$ each of powdered samples was homogenized in $90 \mathrm{ml}$ sterile distilled water in Erlenmeyer flask $(250 \mathrm{ml})$. Dilutions of residue were made with sterilized distilled water and one $\mathrm{ml}$ of aliquot of each sample was then poured in Petri plate containing $10 \mathrm{ml}$ freshly prepared Czapek'sdox agar (CDA) medium. Three replicates of each sample were prepared and incubated $\left(27 \pm 2^{\circ} \mathrm{C}\right)$ for seven days. Different fungal colonies were counted and fungal species were identified on the basis of their cultural and micro-morphological characters using relevant literature and recommended keys (Raper and Fennell, 1965; Booth, 1971; Ellis, 1971; Pitt, 1979). The cultures of fungal isolates were maintained on PDA slants at $4^{\circ} \mathrm{C}$. The occurrence frequency of isolated fungi was determined following Mandeel's (2005) formula.

Extraction of essential oil : For extraction of essential oil, fresh leaves (500 gm) of Cymbopogon citratus were collected from the Botanical Garden, University of Jammu, Jammu. After washing twice with distilled water, leaves were subjected to Clevenger's hydro distillation apparatus ( $3 \mathrm{hrs}$ ). The essential oil was separated and water traces were removed by anhydrous sodium sulphate and stored at $4^{\circ} \mathrm{C}$ in dark for further experiments.

Characterization of $C$. citratus essential oil : The essential oil of $C$. citratus was analyzed through GC equipped with a flame ionization detector. The GC conditions were capillary

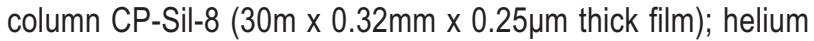
was the carrier gas; injection temperature $280^{\circ} \mathrm{C}$, split ratio 1:150, column oven temperature $50^{\circ} \mathrm{C}$ for $5 \mathrm{~min}$, then $250^{\circ} \mathrm{C}$ held for $7 \mathrm{~min}$. The identification of various compounds was based on their retention times relative to those of standards and matching spectral peaks available.

Antifungal assay : The antifungal activity of essential oil was performed by using poisoned food technique using CDA medium (Perrucci et al., 1994) against seven spoilage moulds (Alternaria alternata, Aspergillus flavus, A. ochraceus, A. parasiticus, $F$. 
graminearum, Penicillium citrinum and $P$. expansum) isolated from dried fruits of $Z$. armatum. Different concentrations of essential oil $\left(0.5-3.0 \mu \mathrm{m} \mathrm{m}^{-1}\right)$ were poured in Petri dishes containing $0.5 \mathrm{ml}$ acetone and $9.5 \mathrm{ml}$ molten CDA. Likewise, CDA plates without essential oil served as control. The plates were then inoculated with discs of test fungi and incubated at $27 \pm 2^{\circ} \mathrm{C}$ for 7 days. Antifungal index was calculated as follows-

Antifungal index $(\%)=(1-\mathrm{Dt} / \mathrm{Dc}) \times 100$

Where, Dt : diameter of growth zone in the test plate; Dc : diameter of growth zone in the control plate.

Determination of MIC and MFC : The minimal inhibitory concentration (MIC) of essential oil of $C$. citratus was recorded against the fungal species by poisoned food technique following Perrucci et al. (1994) at different concentrations of $C$. citratus oil viz., 0.5, 1.0, 1.5, 2.0, 2.5 and $3.0 \mu \mathrm{m} \mathrm{m}^{-1}$. The lowest concentration that did not permit any visible growth was taken as MIC. The inhibited discs of the fungi were sub-cultured on treatment-free PDA plates to find out if the inhibition was reversible. If the mycelial growth was inhibited, the plant extract was fungicidal at this concentration and allowed the determination of minimal fungicidal concentration (MFC).

Detection of aflatoxigenic isolates : Fifty nine isolates identified as $A$. flavus from contaminated dried fruit samples of $Z$. armatum were examined for their aflatoxin $B_{1}\left(A F B_{1}\right)$ producing potential by thin layer chromatography (TLC) (Nabney and Nesbitt, 1965). Each isolate was added to $250 \mathrm{ml}$ Erlenmeyer flask containing 25 $\mathrm{ml}$ SMKY medium (Diener and Davis, 1966) and incubated at $27 \pm 2^{\circ} \mathrm{C}$ for 10 days. The content of each flask was then filtered and extracted with $20 \mathrm{ml}$ chloroform. The extract was evaporated to dryness on water bath and redissolved in one $\mathrm{ml}$ chloroform. Then $50 \mu$ of chloroform extracts were applied on the activated TLC plates. The aflatoxin standard (aflatoxin $B_{1}$ ) was also spotted on TLC plates as reference spots and then developed with solvent system (toluene:isoamyl alcohol:methanol; 90:32:2 v/v). After developing, the plates were air dried and was observed in UVtransilluminator $(360 \mathrm{~nm})$ and their presence were chemically confirmed by spraying $25 \% \mathrm{H}_{2} \mathrm{SO}_{4}$. The intensity of the blue fluorescent spot in the UV transilluminator varies among different aflatoxigenic strains (light blue to deep blue). The toxigenic isolates of $A$. flavus (A-16, A-19 and A-21) produced maximum blue fluorescence under UV light and were, therefore, selected for further investigations. The blue spots were scratched from TLC plates and then dissolved in $5 \mathrm{ml}$ methanol and centrifuged at $3000 \mathrm{rpm}$ for $5 \mathrm{~min}$. Absorbance of the supernatant was recorded at $360 \mathrm{~nm}$ and aflatoxin $B_{1}$ was calculated by the following formula

$$
\text { Aflatoxin } B_{1} \text { content }\left(\mu g I^{-1}\right)=\frac{D \times M}{E \times L} \times 1000
$$

$\mathrm{D}=$ absorbance, $\mathrm{M}=$ molecular weight (312), $\mathrm{E}=$ molar extinction coefficient aflatoxin $B_{1}(21800), L=$ path length $(1 \mathrm{~cm})$
Efficacy of $C$. citratus essential oil for analyzing aflatoxin $B_{1}$ production by $A$. flavus : Required amounts of $C$. citratus essential oil were dissolved in $0.5 \mathrm{ml}$ acetone and added to 24.5 $\mathrm{ml} \mathrm{SMKY} \mathrm{to} \mathrm{achieve} \mathrm{the} \mathrm{various} \mathrm{concentrations} \mathrm{from} 0.5$ to 3.0 $\mu \mathrm{l} \mathrm{m}{ }^{-1}$. The medium inoculated separately with one $\mathrm{ml}$ spore suspension $\left(10^{6}\right.$ spores $\left.\mathrm{ml}^{-1}\right)$ of toxigenic isolates of $A$. flavus (A16, A-19 and A-21) was incubated for ten days at $27 \pm 2^{\circ} \mathrm{C}$. Likewise, control sets were prepared using same amount of distilled water without essential oil. The medium was filtered and mycelium was dried at $80^{\circ} \mathrm{C}$ for $12 \mathrm{hrs}$. Aflatoxin $\mathrm{B}_{1}$ was detected by thin layer chromatography following the method of Nabney and Nesbitt (1965).

Statistical analysis : The statistical significance of the results was analyzed by one way analysis of variance (ANOVA) using SPSS software. Data analyzed were expressed as mean \pm SE. Means were separated by the Tukey's multiple range tests when ANOVAwas significant $(P \leq 0.05)$.

\section{Results and Discussion}

The result of the mycoflora analysis revealed that 64 samples of dried fruit of $Z$. armatum were contaminated with different fungal species (Table 1). A total of 279 isolates belonging to 17 species were recovered from these dried samples. They were represented by 7 genera viz., Acremonium (1sp.), Alternaria (1sp.), Aspergillus (6 spp.), Cladosporium (2 spp.), Mucor (1 sp.), Fusarium (3 spp.) and Penicillium (3 spp.). These species contributed as major fungal components of dried fruits and represented a group of taxa of ubiquitous nature that could exploit almostany substrate and accumulate toxic secondary metabolites.

Analysis of mycoflora indicated genus Aspergillus as the most frequent colonizer that comprised of six species and thus,

Table 1 : Mycoflora analysis of dried fruits of $Z$. armatum

\begin{tabular}{ll}
\hline Fungal species & $\begin{array}{l}\text { Occurrence } \\
\text { frequency (\%) }\end{array}$ \\
\hline Acremonium roseolum (G. Smith) W. Gams & 1.07 \\
Alternaria alternata (Fr.) Keissl. & 4.30 \\
Aspergillus conjuctus (Kwon and Fennell) & 2.86 \\
A. flavus Link & 21.14 \\
A. niger Van Tieghem & 11.47 \\
A. ochraceus Wilhelm & 7.53 \\
A. oryzae (Ahlburg) Cohn & 3.94 \\
A. parasiticus Speare & 10.39 \\
Cladosporium cladosporioides (Fresen.) de Vries & 4.66 \\
C. resinae (Lindau) de Vries & 0.72 \\
Mucor mucedo Fresen. & 0.36 \\
Fusarium camptoceras Wollenweber and Reinking & 3.22 \\
F. graminearum Schwabe & 6.81 \\
F. oxysporum Schlechtendahl & 4.66 \\
Penicillium capsulatum Raper and Fennell & 1.07 \\
P. citrinum Thom & 6.81 \\
P. expansum Link ex Gray & 8.96 \\
\hline
\end{tabular}


Table 2 : Level of aflatoxin $\mathrm{B}_{1}$ production by Aspergillus flavus isolates in SMKY medium

\begin{tabular}{ll}
\hline A. flavus isolates & Concentration $\left(\boldsymbol{\mu} \mathrm{I}^{-1}\right)$ \\
\hline AF-3 & $567.89 \pm 3.21^{*}$ \\
AF-9 & $322.0 \pm 2.98$ \\
AF-16 & $1510.65 \pm 15.87$ \\
AF-17 & $687.07 \pm 3.75$ \\
AF-19 & $1120.87 \pm 5.67$ \\
AF-21 & $1211.0 \pm 2.78$ \\
AF-29 & $299.08 \pm 1.09$ \\
AF-35 & $789.43 \pm 1.21$ \\
AF-41 & $534.89 \pm 2.32$ \\
AF-47 & $245.89 \pm 12.39$ \\
AF-49 & $767.74 \pm 9.89$ \\
AF-56 & $654.01 \pm 2.33$ \\
\hline
\end{tabular}

* mean \pm SE

formed the largest diversity among all the recovered genera. The highest frequency of occurrence was recorded for Aspergillus flavus $(21.14 \%)$ followed by $A$. niger $(11.47 \%)$ and $A$. parasiticus (10.39\%). Owing to their strong competitive ability to produce hydrolytic enzymes and abundant sporulation, the incidence of Aspergillus species usually remains to be high (Bala et al., 2014, 2016; Gupta et al., 2017). In view of the known aflatoxin producing potential of $A$. flavus, 59 isolates of $A$. flavus were evaluated for their aflatoxigenic potency. Out of these, 12 isolates were found toxigenic in nature producing blue fluorescence under UV light. However, three of these toxic isolates namely AF-16, AF-19 and AF-21 produced maximum blue fluorescence under UV light and further subjected to antiaflatoxigenic bioassay. The quantitative analysis revealed that these 12 isolates elaborated aflatoxin $B_{1}$ in the range of $245.89-1510.65 \mathrm{ugl}^{-1}$ (Table 2).

Prior to evaluation of antifungal activity, the Cymbopogon citratus oil was characterized by GC-MS analysis. The essential oil was light yellow in colour and showed the presence of 18 different components. Their retention time and percentage are tabulated in Table 3 and Fig. 1. Monoterpene aldehydes viz., a
Table 3 : Chemical composition of $C$. citratus essential oil

\begin{tabular}{lll}
\hline Components & Percentage (\%) & Retention time (Minutes) \\
\hline Methyl heptenone & 1.33 & 16.774 \\
$\beta$ pinene & 1.99 & 16.998 \\
Limonene & 0.42 & 19.257 \\
Cis Ocimene & 1.54 & 19.509 \\
Linalool & 2.42 & 22.900 \\
(+)- Limonene oxide & 1.77 & 26.062 \\
Cis Verbenol & 3.29 & 27.009 \\
$\beta$ Citral & 26.16 & 29.908 \\
Geraniol & 0.33 & 30.426 \\
a Citral & 49.45 & 31.295 \\
Methyl acetate & 1.01 & 36.168 \\
Methyl eugenol & 3.24 & 37.263 \\
$\beta$ Caryophyllene & 1.24 & 38.372 \\
Germacrene D & 0.46 & 40.944 \\
Cadinene & 0.11 & 42.370 \\
Caryophyllene oxide & 1.12 & 45.122 \\
a Selinene & 1.93 & 48.330 \\
a Bisabolol & 2.12 & 48.823 \\
\hline
\end{tabular}

citral ( 49.45 per cent) and $\beta$ citral ( 26.16 per cent) were the major components of $C$. citratus essential oil accounting for 75.61 per cent of the total oil composition. Percentage of each of the remaining constituents of essential oil was less than 4 percent. Citral has also been found in other medicinal plants like Lippia alba and Cymbopogon khasans (Mishra et al., 2012). The chemical profile of essential oil of a particular plant species is influenced by seasonal, climatic and geographical conditions, plant parts used, time of harvesting and method of isolation, and these chemotypic variations significantly affect the biological efficacy of oil (Shukla et al., 2009; Prakash et al., 2011). Since chemical characterization of essential oil of $C$. citratus in the present study showed citral as its major component, it might have proved effective in retarding the growth of filamentous fungi by inhibiting the mycelial growth through a mechanism of cell membrane damage, compromising its integrity and permeability and inhibition of inter- and extracellular enzymes (De Souza et al., 2005). These measures can occur alone or in blend and

Table 4 : Antifungal index of $C$. citratus essential oil against different fungal species isolated from dried fruits of $Z$. armatum

\begin{tabular}{|c|c|c|c|c|c|c|}
\hline \multirow[t]{3}{*}{ Fungal species } & \multicolumn{6}{|c|}{ Antifungal index ( $\%$ mycelial growth inhibition) } \\
\hline & \multicolumn{6}{|c|}{ Essential oil concentration $\left(\mu \mathrm{l} \mathrm{ml^{-1 } )}\right.$} \\
\hline & 0.5 & 1.0 & 1.5 & 2.0 & 2.5 & 3.0 \\
\hline Alternaria alternata & $45.54 \pm 5.67^{b}$ & $58.32 \pm 1.47^{c}$ & $71.34 \pm 0.85^{c}$ & $85.28 \pm 0.88^{\mathrm{bcd}}$ & $100^{\mathrm{a}}$ & $100^{\circ}$ \\
\hline Aspergillus flavus & $46.01 \pm 0.93^{b}$ & $50.02 \pm 0.56^{d}$ & $68.45 \pm 1.32^{\mathrm{cd}}$ & $81.91 \pm 2.12^{d}$ & $100^{a}$ & $100^{\circ}$ \\
\hline A. ochraceus & $47.72 \pm 0.75^{b}$ & $61.63 \pm 2.34^{\mathrm{bc}}$ & $71.69 \pm 0.86^{c}$ & $88.91 \pm 1.73^{b}$ & $100^{\mathrm{a}}$ & $100^{\circ}$ \\
\hline A. parasiticus & $39.15 \pm 1.65^{\circ}$ & $46.02 \pm 4.56^{\mathrm{de}}$ & $68.05 \pm 3.45^{\mathrm{cd}}$ & $75.19 \pm 0.65^{e}$ & $89.04 \pm 1.37^{b}$ & $100^{\circ}$ \\
\hline Fusarium graminearum & $65.41 \pm 2.45^{\mathrm{a}}$ & $81.03 \pm 0.67^{\mathrm{a}}$ & $100^{\mathrm{a}}$ & $100^{a}$ & $100^{a}$ & $100^{a}$ \\
\hline Penicilllium citrinum & $32.91 \pm 1.53^{d}$ & $42.81 \pm 0.98^{e}$ & $54.09 \pm 1.23^{\mathrm{e}}$ & $71.34 \pm 0.43^{\text {ef }}$ & $89.31 \pm 2.18^{b}$ & $100^{\circ}$ \\
\hline P. expansum & $48.01 \pm 2.34^{b}$ & $66.03 \pm 2.12^{b}$ & $75.01 \pm 3.54^{b}$ & $89.07 \pm 0.78^{b}$ & $100^{\mathrm{a}}$ & $100^{\circ}$ \\
\hline
\end{tabular}

Values represent mean of three replicates $\pm S E$. The mean followed by same letters in the same column are not significantly different according to ANOVA and Tukeys multiple comparison tests 


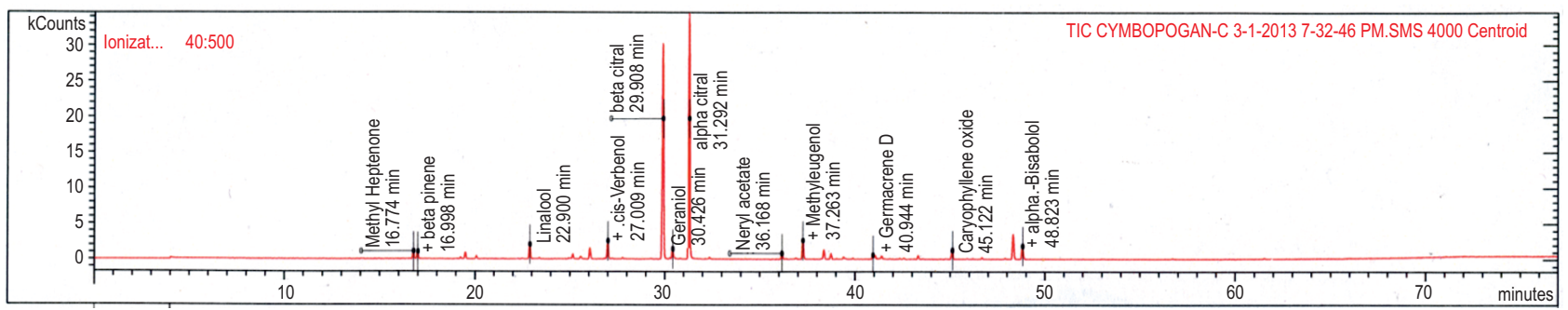

Fig. 1 : GC-MS chromatogram of essential oil of Cymbopogon citratus.

culminate inhibition of mycelium growth (Cowan, 1999). The antifungal activity of citral against moulds and yeasts has already been detected (Belletti et al., 2008; Droby et al., 2008; Adukwu et al., 2016). Palhano et al. (2004) reported that monoterpene (citral) proved effective in controlling mycelial growth and conidial germination of $C$. gloeosporioides. In the present study, besides citral, other constituent compounds like linalool, limonene and geraniol also might have augmented the antifungal potentiality of essential oil of $C$. citratus as confirmed earlier (Hyldgaard et al., 2012). While linalool has been identified to inhibit spore germination by respiratory suppression of aerial mycelia (Matasyoh et al., 2011), geraniol enhances the rate of potassium leakage out of the cells (Bard et al., 1988).

The essential oil of $C$. citratus exhibited pronounced antifungal activity against all the tested fungal species isolated

Table 5 : Minimum inhibitory concentration (MIC) and minimum fungicidal concentration (MFC) of C. citratus essential oil against fungal species

\begin{tabular}{lll}
\hline Fungal species & MIC $\left(\mu \mathrm{ml}^{-1}\right)$ & MFC $\left(\mu \mathrm{ml}^{-1}\right)$ \\
\hline Alternaria alternata & 2.5 & 3.0 \\
Aspergillus flavus & 2.5 & 3.0 \\
A. ochraceus & 2.5 & 3.0 \\
A. parasiticus & 3.0 & $>3.0$ \\
Fusarium graminearum & 1.5 & 2.5 \\
Penicillium citrinum & 3.0 & $>3.0$ \\
P. expansum & 2.5 & 3.0 \\
\hline
\end{tabular}

from dried fruits of Zanthoxylum. The MIC of essential oil was 2.5 $\mu \mathrm{l} \mathrm{m} l^{-1}$ for Alternaria alternata, Aspergillus flavus, A. ochraceus and Penicillium expansum. F. graminearum was most sensitive to essential oil as it was controlled even at $1.5 \mu \mathrm{m} \mathrm{m}^{-1}$, whereas mycelial growth of $A$. parasiticus was inhibited at $3.0 \mu \mathrm{m} \mathrm{m}^{-1}$ (Table 4). The MIC of $C$. citratus essential oil against test fungi was found to be different than some earlier reported essential oils viz., Adenocalymma alliaceum (Shukla et al., 2008) and Anethum graveolens (Prakash et al., 2012). The MFC of essential oil for Alternaria alternata, Aspergillus flavus, $A$. ochraceus and $P$. expansum was recorded at $3.0 \mu \mathrm{ml}^{-1}$ while it was $2.5 \mu \mathrm{ml}^{-1}$ for $F$. graminearum. However, $A$. parasiticus and $P$. citrinum showed $M F C>3.0 \mu \mathrm{ml}^{-1}$, as the revival growth of inhibited mould disc was observed when they were sub-cultured in fresh culture medium suggesting fungistatic nature of test samples (Table 5). These results corroborate earlier reports on the efficacy of essential oil of C. citratus and C. martini signifying strong inhibition of mycelial growth of yeast and other filamentous fungi (Helal et al., 2006; Tzortzakis and Economakis, 2007; Sonker et al., 2014; Kausar et al., 2017). In support of antifungal activity, Singatwadia and Katewa (2001) demonstrated the ability of $C$. citratus essential oil to inhibit the growth of moulds such as Cladosporium sp., Aspergillus niger and Mucor at lower concentrations. Recently, Yooussef et al. (2016) reported that $C$. citratus essential oils exhibited broad fungitoxic activity against Aspergillus parasiticus. The inhibition of fungal mycelial may be due to the occurrence of phenolic compounds in the essential oils. Besides, the lipophilic nature of essential oil allows it to cross

Table 6 : Effect of $C$. citratus essential oil on aflatoxin $B_{1}$ production by $A$. flavus in SMKY medium $\left(\mu \mathrm{g} \mathrm{I}^{-1}\right)$

\begin{tabular}{|c|c|c|c|}
\hline \multirow{2}{*}{$\begin{array}{l}\text { Concentration } \\
\left(\mu \mid \mathrm{ml}^{-1}\right) \\
\end{array}$} & \multicolumn{3}{|c|}{ Aflatoxin $\mathrm{B}_{1}\left(\boldsymbol{\mu g \mathrm { I } ^ { - 1 } )}\right.$} \\
\hline & AF-16 & AF-19 & AF-21 \\
\hline $\mathrm{CN}$ & $1510.65 \pm 15.87^{a}$ & $1120.87 \pm 5.67^{\mathrm{a}}$ & $1211.0 \pm 2.78^{\mathrm{a}}$ \\
\hline 0.5 & $876.0 \pm 3.67^{\circ}$ & $793.65 \pm 14.43^{b}$ & $919.42 \pm 8.54^{b}$ \\
\hline 1.0 & $523.34 \pm 7.89^{c}$ & $124.67 \pm 9.89^{c}$ & $325.31 \pm 4.78^{\circ}$ \\
\hline 1.5 & $0^{d}$ & $0^{d}$ & $156.46 \pm 4.79^{d}$ \\
\hline 2.0 & $0^{d}$ & $0^{d}$ & $0^{\mathrm{e}}$ \\
\hline 2.5 & $0^{d}$ & $0^{d}$ & $0^{e}$ \\
\hline 3.0 & $0^{d}$ & $0^{d}$ & $0^{\circ}$ \\
\hline
\end{tabular}

Values represent mean $(n=3) \pm S E$. The mean followed by same letters in the same column are not significantly different according to ANOVA and Tukeys multiple comparison tests; $\mathrm{CN}$ - control 
the fungal cell membrane and interaction with the membrane enzymes and proteins thereby, creating a flux of protons towards the cell's exterior that alters the cell's and eventually causes death (Bakkali et al., 2008).

The antifungal efficacy of $C$. citratus oil against three toxigenic strains of $A$. flavus (AF-16, AF-19 and AF-21) is summarized in Table 6 . The essential oil inhibited aflatoxin $B_{1}$ production by AF-16, AF-19 and AF-21 at $1.5 \mu \mathrm{m} \mathrm{ml}^{-1}, 1.5 \mu \mathrm{ml}^{-1}$ and $2.0 \mu \mathrm{m} \mathrm{m}^{-1}$, respectively. The essential oil showed inhibition of aflatoxin $\mathrm{B}_{1}$ production at a concentration lower than their MIC for growth of $A$. flavus supporting the findings of earlier workers (Prakash et al., 2012; Mishra et al., 2015). Therefore, the essential oil would be acting by two diverse mode of action (i) inhibitor of fungal growth, and (ii) aflatoxin suppression (Rasooli and Abyaneh, 2004). The chemical constituents of the essentia oils are responsible for the enzymatic modulation and could form a source for their potential antiaflatoxigenic roles (Hajare et al., 2005). Citral, the major component of $C$. citratus essential oil, is widely used natural ingredient and is added to foods, soft drinks and cosmetics as flavouring and fragrance agent. Thus, there would be no chance of off-flavour and harmful effects on sensory quality if the $C$. citratus essential oil is recommended as plant based food additive for complete prevention against quantitative losses from food-borne fungi, qualitative losses due to aflatoxins and as an alternative to synthetic preservative to improve the storage life of dried commodities.

\section{Acknowledgments}

The authors are thankful to the Head, Department of Botany (SAP-DRS-II), University of Jammu, Jammu for providing necessary laboratory facilities and UGC- BSR (F-25-1/2013-14 (BSR)/11-57/2007) for providing financial assistance.

\section{References}

Adukwu, E.C., M. Bowles, V.E. Jones and H. Bone: Antimicrobial activity, cytotoxicity and chemical analysis of lemongrass essential oil (Cymbopogon flexuosus) and pure citral. Appl. Microbiol. Biotechnol., 100, 9619-9627 (2016).

Bakkali, F., S. Averbeck, D. Averbeck and M. Idaomar : Biological effects of essential oils-A review. Food Chem. Toxicol., 46, 446-475 (2008).

Bala, P., D. Gupta and Y.P. Sharma: Mycoflora and natural aflatoxin contamination in dried quince seeds from Jammu, India. J. Environ. Biol., 37, 101-106 (2016).

Bala, P., D. Gupta and Y.P. Sharma: Mycobiota and aflatoxin $\left(B_{1}\right.$ and $\left.B_{2}\right)$ contamination of apricot kernels Prunus armeniaca $\mathrm{L}$. from Jammu and Kashmir, India. Environ. Conserv. J., 15, 69-76 (2014).

Bard, M., M.R. Albrecht, N. Gupta, C.J. Guynn and W. Stillwell: Geraniol interferes with membrane functions in strains of Candida and Saccharomyces. Lipids, 23, 534-538 (1988).

Belletti, N., R. Lanciotti, F. Patrignani and F. Gardini: Antimicrobial efficacy of citron essential oil on spoilage and pathogenic microorganisms in fruit-based salads. J. Food Sci., 73, 331-338 (2008).

Booth, C.: The genus Fusarium. CMI, Kew, Surrey, England, pp. 237 (1971)
Brent, K.J. and D.W. Hollomon : Fungicide resistance: The assessment of risk. FRAC, Global Crop Protection Federation, Brussels. Monograph No. 2, p. 48 (1998).

Burt, S.: Essential oils: their antibacterial properties and potential application in foods-A review. Int. J. Food Microbiol., 94, 223-253 (2004).

Chang, S.K., C. Alasalvar and F. Shahidi: Review of dried fruits: Phytochemicals, antioxidant efficacies and health benefits. J. Funct. Foods, 21, 113-132 (2016).

Cowan, M.M.: Plant products as antimicrobial agents. Clin. Microbiol. Rev., 12, 564-582 (1999).

De Souza, E.L., E.O. Lima, K.R. Friere and C.P. Sousa: Inhibitory action of some essential oils and phytochemicals on the growth of various moulds isolated from foods. Braz. Arch. Biol. Technol., 48, 245-250 (2005).

Diener, U.L. and N.D. Davis: Aflatoxin production by isolates of Aspergillus flavus. Phytopathol., 56,1390-1393 (1966).

Droby, S., A. Eick, D. Macarisin, L. Cohen, G. Rafael, R. Stange, G McColum, N. Dudai, A. Nasser, M. Wisniewski and R. Shapira: Role of citrus volatiles in host recognition, germination and growth of Penicillium digitatum and Penicillium italicum. Postharvest Biol. Technol., 49, 386-396 (2008).

Ellis, M.B.: Dematiaceous hyphomycetes. Commonwealth Mycological Institute (CMI), Kew, Surrey, England, p. 608 (1971).

El-Nagerabi, S.A.F., A.E. Elshafie, S.S. Alkhanjari, S.N. AL-Bahry and M.R. Elamin: The potential of baobab (Adansonia digitata L.) extracts as biocontrol on the growth and aflatoxin production by Aspergillus flavus and A. parasiticus. J. Food Res., 2, 93-103 (2013).

Gandomi, H., A Misaghi, A.A. Basti, S. Bokaei, A. Khosravi, A. Abbasifar and A.J. Javan: Effect of Zataria multiflora Bioss. essential oil on growth and aflatoxin formation by Aspergillus flavus in culture media and cheese. Food Chem. Toxicol., 47, 2397-2400 (2009).

Gupta, D., P. Bala and Y.P. Sharma: Evaluation of fungal flora and mycotoxin contamination in whole dried apricots (Prunus armeniaca L.) from J\&K, India. Pro. Nat. Acad. Sci, India Section B: Biol. Sci., 87, 81-87 (2017).

Hajare, S.S., S.N. Hajare and A. Sharma: Aflatoxin inactivation using aqueous extract of ajowan (Trachyspermum ammi) seeds. J. Food Sci., 70, 29-34 (2005).

Helal, G.A., M.M. Sarhan, A.N.K. Abu Shagla and E.K. Abou El-Khair: Effects of Cymbopogon citratus L. essential oil on the growth, lipid content and morphogenesis of Aspergillus niger ML2-strain. J. Basic Microbiol., 46, 456-469 (2006).

Hyldgaard, M., T. Mygind and R.L. Meyer: Essential oils in food preservation: Mode of action, synergies, and interactions with food matrix components. Front. Microbiol., 3, 1-42 (2012).

Jayashree, T. and C. Subramanyam: Oxidative stress as a prerequisite for aflatoxin production by Aspergillus parasiticus. Free Radi. Biol. Med., 29, 981-985 (2000).

Kausar, R., S. Kausar and S. Chiragh: In vitro antifungal activity of Aloe vera and Cymbopogon citratus against Candida albicans. Biomed., 33, 1-3 (2017).

Mandeel, Q.A. : Fungal contamination of some imported spices. Mycopath., 159, 291-298 (2005).

Manvitha, K. and B. Bidya: Review on pharmacological activity of Cymbopogon citratus. Int. J. Herbal Med., 1, 5-7 (2014).

Matasyoh, J.C., I.N. Wagara, J.L. Nakavuma and A.M. Kiburai: Chemical composition of Cymbopogon citratus essential oil and its effect on mycotoxigenic Aspergillus species. Afr. J. Food Sci., 5, 138-142 (2011)

Mishra, P.K., B. Prakash, A. Kedia, A.K. Dwivedy, N.K. Dubey and S Ahmad: Efficacy of Caesulia axillaris, Cymbopogon khasans and Cymbopogon martinii essential oils as plant based preservatives 
against degradation of raw materials of Andrographis paniculata by fungal spoilage. Int. Biodeter. Biodegrad., 104, 244-250 (2015).

Mishra, P.K., R. Shukla, P. Singh, B. Prakash, A. Kedia and N.K. Dubey: Antifungal, anti-aflatoxigenic, and antioxidant efficacy of Jamrosa essential oil for preservation of herbal raw materials. Int. Biodeter. Biodegrad., 74, 11-16 (2012).

Mosquera, T.T., N.R. Paco, C.C. Juan and M.de.L. Pardo: Biological activity of Cymbopogon citratus (DC.) Stapf and its potential cosmetic activities Int. J. Phytocosmetics Nat. Ingr., 3, 1-7 (2016).

Nabney, J. and B.F. Nesbitt: A spectrophotometric method for determing the aflatoxins. Analyst, 90, 155-160 (1965).

Oliveira, P.D.L., K.A.R. de Oliveira, W.A.D.S. Vieira, M.P. S. Camara and E.L. de Souzaa: Control of anthracnose caused by Colletotrichum species in guava, mango and papaya using synergistic combinations of chitosan and Cymbopogon citratus (D.C. ex Nees) Stapf. essential oil. Int. J. Food Microbiol., 266, 87-94 (2018).

Palhano, F.L., T.T. Vilches, R.B. Santos, M.T. Orlando, J.A. Ventura and P.M. Fernandes: Inactivation of Colletotrichum gloeosporioides spores by high hydrostatic pressure combined with citral or lemon grass essential oil. Int. J. Food Microbiol., 95, 61-66 (2004).

Perrucci, S., F. Mancianti, P.L. Ciont, G. Flamini, I. Morelli and G. Macchioni : In vitro antifungal activity of essential oils against some isolates of Microsporum canis and M. gypseum. Planta Medica, 60, 184-187 (1994).

Pitt, J.I.: The genus Penicillium and its teleomorphic states Eupenicillium and Talaromyces. CSIRO Division of Food Research, Academic Press, (Harcourt Brace Jovanovich Publishers), London, p. 634 (1979).

Prakash, B., P. Singh, A. Kedia, A.K. Dwivedy A. Singh and N.K. Dubey: Mycoflora and aflatoxin analysis of Arachis hypogea L. and assessment of Anethum graveolens $L$. seed and leaf essential oils against isolated fungi, aflatoxin production and their antioxidant activity. J. Food Safety, 32, 481-491 (2012).

Prakash, B., R. Shukla, P. Singh, P.K. Mishra, N.K. Dubey and R.N. Kharwar: Efficacy of chemically characterized Ocimum gratissimum $\mathrm{L}$. essential oil as an antioxidant and a safe plant based antimicrobial against fungal and aflatoxin $\mathrm{B}_{1}$ contamination of spices. Food Res. Int., 44, 385-390 (2011).

Raper, E.B. and D.I. Fennell: The genus Aspergillus. The Williams and Wilkins Company, Baltimore, USA, p. 575 (1965).

Rasooli, I. and M.R. Abyaneh: Inhibitory effects of Thyme oils on growth and aflatoxin production by Aspergillus parasiticus. Food Contr., 15, 479-483 (2004).

Shukla, R., A. Kumar, C.S. Prasad, B. Srivastava and N.K. Dubey: Antimycotic and antiaflatoxigenic potency of Adenocalymma alliaceum Miers. on fungi causing biodeterioration of food commodities and raw herbal drugs. Int. Biodeter. Biodegr., 62, 348351 (2008).

Shukla, R., A. Kumar, P. Singh and N.K. Dubey: Efficacy of Lippia laba (Mill.) N.E. brown essential oil and its monoterpene aldehydes constituents against fungi isolated from some edible legume seeds and aflatoxins production. Int. J. Food Microbiol., 135, 165-170 (2009).

Singatwadia, A. and S.S. Katewa: In vitro studies on antifungal activity of essential oil of Cymbopogon martini and Cymbopogon citratus. Ind. Perfum., 45, 53-55 (2001).

Singh, K., J.C. Frisvad, U. Thrane and S.B. Mathur: An illustrated manual on identification of some seed borne Aspergilli, Fusaria, Penicilla and their mycotoxin. Danish Government Institute of Seed Pathology for Developing Countries, Hellerup, p.133 (1991).

Sonker, N., A.K. Pandey, P. Singh and N.N. Tripathi: Assessment of Cymbopogon citratus (DC.) Stapf essential oil as herbal preservatives based on antifungal, antiaflatoxin and antiochratoxin activities and in vivo efficacy during storage. J. Food Sci., 79, 628$634(2014)$

Tzortzakis, N.G. and C.D. Economakis: Antifungal activity of lemongrass (Cymbopogon citratus L.) essential oil against key postharvest pathogen. Innovative Food Sci. Emerg. Technol., 8, 253-258 (2007).

Udomkun, P., A. M. Wiredu, M. Nagle, J. Muller, B. Vanlauwe and R. Bandyopadhyay: Innovative technologies to manage aflatoxins in foods and feeds and the profitability of application-A review. Food Contrl., 76, 127-138 (2017).

Vinson, J.A., L. Zubik, P. Bose, N. Samman and J. Proch: Dried fruits : excellent in vitro and in vivo antioxidants. J. Am. Coll. Nutr., 24, 4450 (2005).

Weckesser, S., K. Engel, B. Simon-Haarhaus, A. Wittmer, K. Pelz and C.M. Schempp: Screening of plant extracts for antimicrobial activity against bacteria and yeast with dermatological relevance. Phytomed., 14, 508-516 (2007).

Yooussef, M.M., Q. Pham, P.N. Achar and M.Y. Sreenivasa: Antifungal activity of essential oils on Aspergillus parasiticus isolated from peanuts. J. Plant Protect. Res., 56, 139-142 (2016). 